\title{
A STUDY ON TREATMENT PATTERN AND OUTCOMES OF POISONING CASES IN A TERTIARY CARE AND GOVERNMENT DISTRICT HOSPITAL
}

\author{
PATHAN AMANULLA KHAN ${ }^{1}$, DILEEP CHARY M. ${ }^{2 *}$, M. MANOJ KUMAR ${ }^{3}$, B. B. SARAH NOUSHEEN ${ }^{4}$ \\ ${ }^{1}$ Assistant professor, Department of Clinical Pharmacy and Pharmacy Practice, Anwarul Uloom College of Pharmacy, Hyderabad, Telangana, \\ India, ${ }^{2}$ Pharm D Intern, Department of Pharmacy Practice, SJM College of Pharmacy, Chitradurga, Karnataka, India, ${ }^{3}$ Department of Pharmacy \\ Practice, SJM College of Pharmacy, Chitradurga, Karnataka, India, ${ }^{4}$ Anwar-ul Uloom College of Pharmacy, Hyderabad, Telangana, India \\ Email: srujansai.262@gmail.com
}

Received: 20 Jan 2017 Revised and Accepted: 27 Feb 2017

\begin{abstract}
Objective: Poisoning is a major prevalent problem, with thousands of deaths occurring every year, mainly in developing countries. The present study sought to identify the treatment pattern and outcomes of poisoning cases admitted to Basaveshwara Medical College and Hospital and Research Centre (BMCH and RC) and Government District Hospital and to determine the type of poison cases.
\end{abstract}

Methods: This is a prospective observational study aimed to analyse the poisoning cases admitted to general medicine departments and emergency departments of BMCH and RC and Government District Hospital, Chitradurga, Karnataka for a period of six months.

Results: A total of 100 cases were enrolled in this study. $63 \%$ of the cases were identified from BMCH and RC, with the remainder being from Government Hospital. The study shows that $41 \%$ of the cases were $21-30$ y old. $48 \%(\mathrm{n}=48)$ were males and $52 \%(\mathrm{n}=52)$ were females. Different types of poisoning cases were observed; organophosphorus poisoning (OP) taking the lead, followed by snake bite cases. The study denotes a mortality rate of $4 \%$ and morbidity rate of $96 \%$. A majority of cases were reported in the second quarter of the year.

Conclusion: It was concluded from the above findings that young age adults constituted a significant percentage of the subjects. It is essential, therefore, to propose policies that can terminate the free trade of poisonous pesticides and to create awareness and periodically counsel the vulnerable group of the population.

Keywords: Poisoning, Organophosphorus (OP), Pesticides

(C) 2017 The Authors. Published by Innovare Academic Sciences Pvt Ltd. This is an open access article under the CC BY license (http://creativecommons.org/licenses/by/4.0/] DOI: http://dx.doi.org/10.22159/ijpps.2017v9i4.17196

\section{INTRODUCTION}

Poison is an agent which, when administered into the body of a living being, can elicit a toxic response producing damage and resulting in death. A therapeutic substance is considered to be a poison if sufficiently larger doses are introduced into the body [1]. Poisoning has been a matter of serious concern globally since time immemorial, accounting for over a million deaths every year $[2,3]$, particularly in low and middle-income countries [4]. Acute poisoning is deemed a vital medical crisis, demanding immediate admission into an intensive care unit $[5,6]$. Feasibility of a specific drug, its relative potency, socio-economic complexity of a population and the provision of primary care to patients are some aspects which govern the severity and management of poisoning cases [7].

In advanced countries, the main triggers for poisoning are drugs, either prescription dispensed or over-the-counter (OTC) and household chemicals $[4,7,8]$, whereas in the Indian subcontinent, agriculture being the foremost occupation, the most notorious etiologic agents include pesticides and other agro based fertilizers, followed by hypnotics and sedatives, corrosive reagents, alcohol, plant poisons and household chemicals $[3,4,7,8]$. A vast majority of cases in the developing countries arise from organophosphorus poisoning, resultant from occupational, coincidental or deliberate subjection of farmers or other workers to toxic agents [8-10].

The WHO estimates over 3 million fatalities occurring annually as a result of self-administration of pesticides. This can be minimised by restricting accessibility of these chemicals to the common man $[2,6]$. Victims of intentional poisoning were mostly children, whereas suicidal poisoning was the favoured method of self-annihilation among adults $[4,5,8,11,12]$.

Snake bite is another hazard that adds to public concern of poisons. Nearly 5 million venom bites are reported every year, with a minimum of 100000 fatalities. India accounts for about 50000 deaths from snake bites annually [2].

Anxiety, depression, unemployment, seclusion, failure in examinations, marital disharmonies, etc. are some of the augmenting factors for self-poisoning $[4,10,13,14]$. In view of the increasing suicides in the country by poisoning, the Government of India enacted The Poisons Act in 1919, governing the trade of poisons and authorizing licensed personnels the sole custodians of poisonous drugs [3].

Therefore, the objectives of the present research were to study the treatment patterns and outcomes of poisoning cases admitted to $\mathrm{BMCH}$ and RC and Government Hospital and to determine the type of poison cases.

\section{MATERIALS AND METHODS}

\section{Study site}

This study was conducted at Basaveshwara Medical College Hospital and Research Centre and at government district hospital, Chitradurga, Karnataka.

\section{Study approval}

This study was approved by the Institutional Human Ethical Committee [Ethical committee number: SJMCP/IEC/1101/2015-16 dated 07/12/15] of the SJM College of Pharmacy, Chitradurga.

\section{Study design}

This is a prospective observational study conducted to analyse the poisoning cases admitted to general medicine departments and emergency departments of $\mathrm{BMCH}$ and $\mathrm{RC}$ and government district hospital, Chitradurga. 


\section{Study period}

The study was conducted for a period of six months, from April 2015 to September 2015.

\section{Study subjects}

The study includes hospital in-patients treated with poison treatment. Patients who met the following criteria were enrolled.

\section{Study criteria}

Inclusion criteria

- Patients admitted to hospital on poisoning condition

- Patients of either sex

\section{Exclusion criteria}

- Patients not willing to participate and provide consent form were excluded from the study

- Pregnancy and lactating women

\section{Study materials}

Patient data collection form: It included demographic details of the patient like IP number, age, gender, diagnosis, treatment chart.

\section{Study procedure and collection of data}

A prospective observational study was conducted on patients admitted to emergency and general medicine departments, who were diagnosed as suffering from poisoning. A suitable data collection form, provided and intended to collect the required data for the study, including patients' medical records and case sheets was then reviewed. Data regarding patient demographics, type of poison, route of exposure (oral, inhalation, dermal), name of poison consumed, clinical presentation, investigations performed, time elapsed after poison intake, outcomes of poisoning, duration of hospitalization, treatment specified, specific antidote given, complications developed, treatment outcomes and events of mortality were then recorded and studied.

\section{Statistical analysis}

Statistical analysis was performed using MS Office.

\section{Source of data}

- Prescription orders and medical records of patients

- Lab data

- Case sheets of patients

\section{RESULTS}

\section{Total number of cases collected}

In the present study, 100 cases of either sex were collected, of which $63 \%(\mathrm{n}=63)$ were obtained from $\mathrm{BMCH}$ and $\mathrm{RC}$ and the remaining $37 \%(n=37)$ from Government hospital. Fig. 1 represents, in the form of a pie chart, the number of cases procured from both the hospitals.

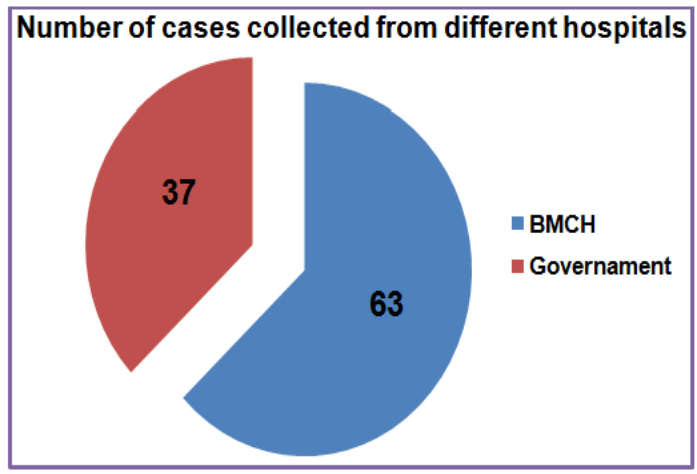

Fig. 1: Number of cases collected from different hospitals

\section{Gender wise distribution of data}

From the 100 cases, females (52\%) outnumbered males (48\%) in both the hospitals. Males comprised of $30 \%$ and $18 \%$ of the total number from $\mathrm{BMCH}$ and $\mathrm{RC}$ and government hospital respectively whereas females constituted $33 \%$ and $19 \%$ of the total from the same.

Table 1 demonstrates the gender wise distribution of data.

Table 1: Number of cases by gender

\begin{tabular}{lllll}
\hline Hospital name & Male & Percentage (\%) & Female & Percentage (\%) \\
\hline BMCH & 30 & 30 & 33 & 33 \\
Government & 18 & 18 & 19 & 19 \\
Total & 48 & 48 & 52 & 52 \\
\hline
\end{tabular}

\section{Monthly distribution of data}

Our study was timed for a duration of 6 mo i.e., from April to September 2015. A significantly larger number of cases were noted in the month of June (26), followed by May (20). Minimum cases were reported in the month of September (7).

The monthly distribution of data is presented in table 2 .

Table 2: Monthly distribution of data by hospitals

\begin{tabular}{|c|c|c|c|c|c|c|}
\hline Month & ВMCH & $\%$ & Government & $\%$ & Total & $\%$ \\
\hline April & 11 & 11 & 5 & 5 & 16 & 16 \\
\hline May & 10 & 10 & 10 & 10 & 20 & 20 \\
\hline June & 19 & 19 & 7 & 7 & 26 & 26 \\
\hline July & 13 & 13 & 4 & 4 & 17 & 17 \\
\hline August & 6 & 6 & 8 & 8 & 14 & 14 \\
\hline September & 4 & 4 & 3 & 3 & 7 & 7 \\
\hline Total & 63 & 63 & 37 & 37 & 100 & 100 \\
\hline
\end{tabular}

\section{Age groups}

We categorized the cases by age groups and analysed the results. There were more number of cases between 21 and $30 \mathrm{y}$ of age, i.e.,
$41 \%$ of the total. This was proceeded by the age group of $31-40 \mathrm{y}$ (18\%).

Age wise distribution of data with respect to gender is tallied in table 3. 
Table 3: Represents age group of patients with respect to gender

\begin{tabular}{|c|c|c|c|c|c|c|}
\hline Age group & Male & $\%$ & Female & $\%$ & Total & $\%$ \\
\hline $0-10 y$ & 4 & 4 & 5 & 5 & 9 & 9 \\
\hline $11-20 y$ & 7 & 7 & 7 & 7 & 14 & 14 \\
\hline $21-30 y$ & 15 & 15 & 26 & 26 & 41 & 41 \\
\hline $31-40 y$ & 8 & 8 & 10 & 10 & 18 & 18 \\
\hline $41-50 y$ & 9 & 9 & 4 & 4 & 13 & 13 \\
\hline $51-60 y$ & 5 & 5 & 0 & 0 & 5 & 5 \\
\hline Total & 48 & 48 & 52 & 52 & 100 & 100 \\
\hline
\end{tabular}

\section{Poison cases collected from different hospitals}

In this study, different types of poisoning cases were evinced in patients admitted to the emergency departments of medicine of both hospitals. Organ phosphorus poisoning cases (40\%) took the lead in either hospital, followed by snake bite cases (22\%) while the least encountered were those caused by Nerium seed consumption (5\%).

Table 4 represents the prevalence of poisoning cases in different hospitals

Table 4: Type of poison with respect to hospital

\begin{tabular}{|c|c|c|c|c|c|c|}
\hline Type of poison & BMCH & $\%$ & Government & $\%$ & Total & $\%$ \\
\hline $\mathrm{OP}$ & 32 & 32 & 18 & 18 & 50 & 50 \\
\hline Snake bites & 13 & 13 & 9 & 9 & 22 & 22 \\
\hline Stings & 11 & 11 & 5 & 5 & 16 & 16 \\
\hline Honey bee bites & 4 & 4 & 3 & 3 & 7 & 7 \\
\hline Nerium seeds & 3 & 3 & 2 & 2 & 5 & 5 \\
\hline Total & 63 & 63 & 37 & 37 & 100 & 100 \\
\hline
\end{tabular}

\section{Type of poisoning against gender}

From a sum of 100 cases, 52\% female and 48\% male cases were documented. Greater prevalence of OP poisoning cases $(50 \%)$ was seen, the successors being snake bite cases (22\%), stings (16\%), honey bee bites (7\%) and Nerium seed consumption (5\%). A gender wise analysis shows more preponderance of females to OP poisoning. Snake bite cases were observed more in the opposite sex, followed by strings.

Table 5 shows the type of poisoning with respect to gender.

Table 5: Prevalence of poisoning by gender

\begin{tabular}{|c|c|c|c|c|c|c|}
\hline Type of poison & Male & $\%$ & Female & $\%$ & Total & $\%$ \\
\hline OP & 21 & 21 & 29 & 29 & 50 & 50 \\
\hline Snake bites & 13 & 13 & 9 & 9 & 22 & 22 \\
\hline Stings & 9 & 9 & 7 & 7 & 16 & 16 \\
\hline Honey bee bites & 3 & 3 & 4 & 4 & 7 & 7 \\
\hline Nerium seeds & 2 & 2 & 3 & 3 & 5 & 5 \\
\hline Total & 48 & 48 & 52 & 52 & 100 & 100 \\
\hline
\end{tabular}

\section{Therapeutic category against poison cases}

In this study, 397 drugs were prescribed other than IV fluids. The average number of drugs per prescription was found to be 3.97 . The drugs most commonly given included antibiotics, PPIs, anti- cholinergics, $\mathrm{H}_{2}$ antihistaminics, anti-emetics, anti-amoebics, NSAIDs, anti-snake venom and others.

Table 6 shows the frequency of therapeutic drugs indicated in poisoning cases.

Table 6: Therapeutic category by frequency

\begin{tabular}{lll}
\hline Therapeutic category & Frequency & Percentage (\%) \\
\hline Antibiotics & 69 & 17.38 \\
Proton pump inhibitors & 57 & 14.35 \\
Anti-cholinergics & 43 & 10.83 \\
$\mathrm{H}_{2}$-anti histaminics & 41 & 10.32 \\
Anti-emetics & 29 & 7.30 \\
Anti-amoebics & 27 & 6.80 \\
NSAIDs & 23 & 5.79 \\
Anti-snake venom & 9 & 2.26 \\
Other medications & 99 & 24.93 \\
Total & 397 & 100 \\
\hline
\end{tabular}

Atropine and pralidoxime were most commonly administered to patients with OP consumption. Prazosin was given to some patients with stings. Anti-histaminics and sedatives were also used for the latter group of patients.
NSAIDs were given to individuals suffering from pain. Snake bites were treated with anti-snake venom. Outcomes of poisoning cases of the 100 cases collected, $96 \%$ morbidity and $4 \%$ mortality was reported. 


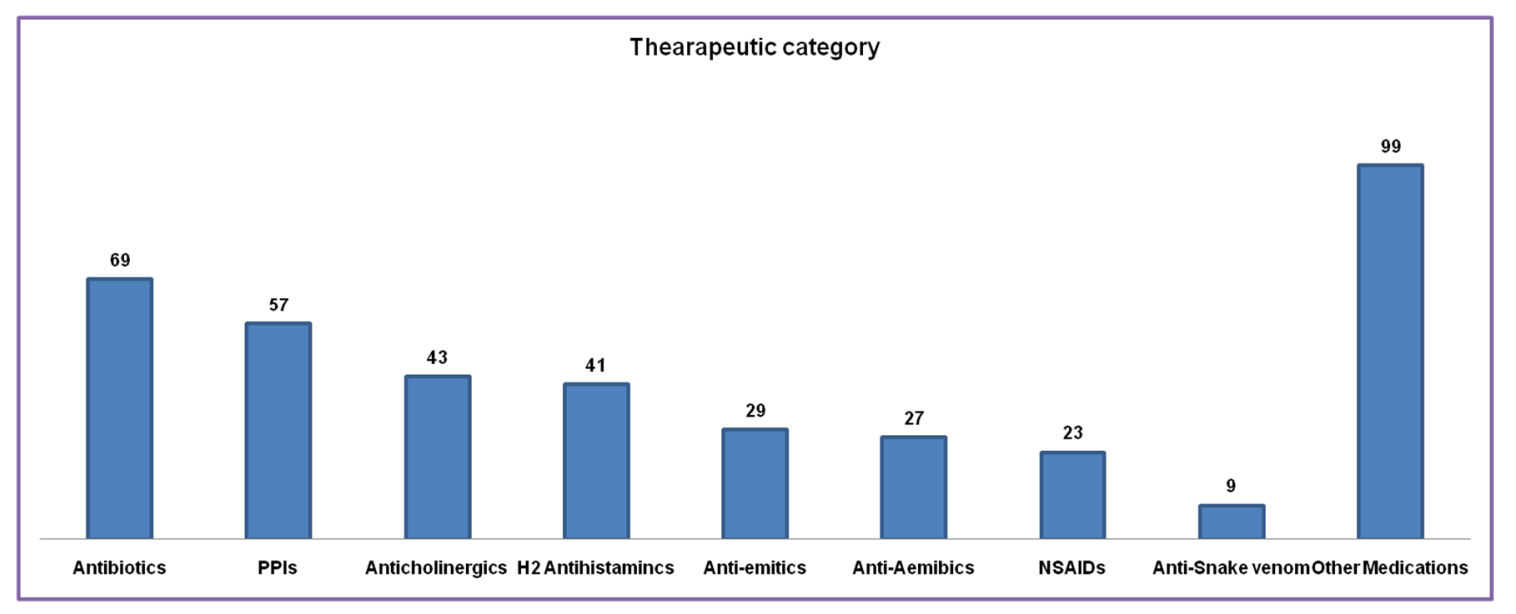

Fig. 2: Therapeutic category by frequency

Table 7: Poisoning vs. outcomes

\begin{tabular}{lll}
\hline Type of poison & Cure & Death \\
\hline OP & 48 & 02 \\
Snake bites & 20 & 02 \\
Stings & 16 & 00 \\
Honey bee bites & 07 & 00 \\
Nerium seeds & 05 & 00 \\
Total & 96 & 04 \\
Percentage & $96 \%$ & $4 \%$ \\
\hline
\end{tabular}

\section{DISCUSSION}

Globally, more than 800000 people commit suicide every year, 30\% of which are due to pesticide poisoning [15]. An estimated 3 million morbidities of pesticide poisoning are reported to the WHO every year, resulting in the loss of over 220000 lives. The past few decades have witnessed outstanding improvements in the agricultural and medicinal sectors introducing novel and more potent pesticides and drugs. Unlimited and unsafe usage of these chemicals due to insufficient knowledge and apprehension leads to poisoning [4].

The present study comprises of 100 subjects of either sex, from two different hospitals, i.e., Basaveshwara Medical College and Hospital and Research Centre (BMCH and RC) and District Government Hospital of Chitradurga, Central Karnataka, diagnosed as suffering from poisoning. The study was carried out for a duration of 6 mo. $63 \%$ and $37 \%$ cases were collected from the $\mathrm{BMCH}$ and $\mathrm{RC}$ and government hospital respectively.

Our study reports a higher preponderance of women (52\%) compared to men (48\%). This is consistent with the results of other studies [6, 13 , 14]. Higher prevalence among females is attributable to the depressive situations women face such as domestic violence, marital conflicts or experiencing dishonour due to in-laws. Under such pressurized circumstances, women resort to committing suicide by poisoning themselves. Therefore, the availability of these chemicals is also a matter of concern [14]. On the contrary, several other studies report a higher percentage in males $[4,5,7-9,11,16]$ owing to persistent financial burden, extra-marital relationships or occupational subjection. Hamida Jamil, in her study, notifies the higher occurrence of poisoning among unmarried men and married women [6].

In the six month duration from April to September, a large number of cases were reported to have occurred in the month of June, followed by May. The results coincide with the study conducted by Karki et al. in Nepal. The Greater prevalence of cases in the rainy season is resultant from easy accessibility of pesticides in this season or from instability in climatic conditions, posing problems to the farmers either due to heavy or insufficient downpour, thereby causing exasperation among them [17]. However, few other studies contradict this finding $[4,16]$. Kanchan et al. reports more female cases in the initial 3 mo of the year and more male cases in the months from April-June [11].

Our study demonstrates that the third decade of life is most likely to succumb to poisoning. Other studies suggest similar results $[4,5,8$, $9,11,17-19]$. This conclusion can be rationalized from the certitude that the age group of 21-30 y is the determining interval of life. Hence, these persons are more prone to traumatic affairs. Career, unemployment, relationship distress, solitude, financial crisis, fear of failure or failure itself, life settlement factors, etc. are the various triggers that urge this batch of youth to end their lives, without further considering to ponder over the issue [13]. The second most susceptible beings were those in the age group of 31-40 y as was consistent with the findings of other publishings $[10,17]$.

This was followed by the category of teens, i.e., 11-20 y, probable from immaturity. Children occupied the fifth position with $17.94 \%$ of the total subjects, credited to accidental exposure [12]. The age group of 51-60 y and above accounted for minimum cases, corresponding with the results of others $[4,10,17]$.

The present study constitutes 5 different types of poisoning cases. These, in the order of their descent, can be categorized as follows: OP poisoning (50\%), snake bites (22\%), stings $(16 \%)$, honey bee bites (7\%), Nerium seeds (5\%). The results were in concordance with other researches $[4,5,8-10,16-18]$. This may be due to long standing exposure to these agrochemicals, or due to inadequate self-protection $[4,5,11,12,16,17]$. However, the present study reveals a greater percentage of women falling victim to OP poisoning, indicative from the fact that women, in the Indian community, face several postmarital hardships which compel them to quit [9]. Snake bites (22\%) and stings $(16 \%)$ rank second in the list and occur more frequently in males than in females. The attributable factor in this regard is the workplace of the farm workers. Thick and dense grasslands render them readily prone to insect bites.

Patients with the various types of poisonings were immediately admitted to the emergency medicine departments. Gastric lavage was performed in $35 \%$ of the patients. 397 drugs were prescribed to the 100 patients, excluding IV fluids. The average number of drugs per prescription was found to be $3.97 \approx 4$. Antibiotics were given 
most frequently, followed by PPIs, anticholinergics, $\mathrm{H}_{2}$-antihistaminics, anti-emetics, anti-amoebics, NSAIDs and anti-snake venom. Apart from these, 99 variant medications were provided. $17.38 \%$ antibiotics were authorized for use in the majority of the cases, which comprised of ceftriaxone, cefpodoxime, cefixime, levofloxacin and combinations such as piperacillin+tazobactam and ceftriaxone+salbactam. Anti-cholinergic injection atropine and the antidote pralidoxime iodide $17 \%$ were mostly used for OP poisoning. Stings were commonly treated with antihistamines and sedatives, prazosin being provided to some patients. Anti-amoebics such as metronidazole were also used. Anti-snake venom, Inj. ASV was prescribed after diluting with normal saline. Antidote charcoal was employed in 3\% of the patients. Maintenance of blood pressure and electrolytes was carried out during gastric lavage, with the aid of intravenous fluids like normal saline 5\%,25\%, dextrose and ringer lactate solution. The outcome of this study signifies a morbidity rate of $96 \%$ and $4 \%$ mortality rate. The extended time lapse between poison intake and hospital admission and provision of instant management are the factors affecting mortality rate.

\section{CONCLUSION}

It was revealed from the present study that females outnumbered males in both the hospital settings. Maximum numbers of cases were reported in the rainy season. Organophosphorous poisoning was observed to be the most common method. 21-30 y olds were most prone to suicidal poisoning, ascribed to their perturbation concerning future issues. Limitations of this study include small sample size, which can be justified from the reluctance of patients to participate in the research. This study illustrates the necessity of curtailing the illicit marketing of poisonous pesticides, OP compounds in particular. Disseminating knowledge regarding the safe use of pesticides and drugs is important to prevent accidental cases. Patients with psychosocial problems should be recognised at the earliest and should be provided proper counselling.

\section{ACKNOWLEDGEMENT}

We thank the staff members of Basaveshwara Medical College and Hospital and Research Centre (BMCH and RC) and the Government District Hospital, Chitradurga, Karnataka, India for their help and support. The authors also thank SJM College of Pharmacy for assisting in the research work.

\section{ABBREVIATION}

BMCH and RC: Basaveshwara Medical College and Hospital and Research Centre, OP: Organophosphorus, OTC: Over-the-counter, WHO: World Health Organization, PPIs: Proton pump inhibitors, NSAIDs: Non-steroidal anti-inflammatory drugs, ASV inj.: Anti-snake venom injection.

\section{CONFLICT OF INTERESTS}

All authors have none to declare

\section{REFERENCES}

1. Levine RR, Walsh CT, Schwartz-Bloom RD. editors. Pharmacology: Drug Actions and Reactions. $7^{\text {th }}$ ed. CRC Press; 2000.
2. World Health Organization. International Programme on Chemical Safety: Poisoning Prevention and Management. Available from: http://www.who.int/ipcs/poisons/en/. [Last accessed on 10 Jan 2017]

3. Pillay VV. Modern Medical Toxicology. $4^{\text {th }}$ ed. New Delhi: Jaypee Brothers Medical Publishers (P) Ltd; 2013.

4. Jailkhani SMK, Naik JD, Thakur MS, Langare SD, Pandey VO. Retrospective analysis of poisoning cases admitted in a tertiary care hospital. Int J Recent Trends Sci Technol 2014;10:365-8.

5. Ramesha KN, Rao KBH, Kumar GS. Pattern and outcome of acute poisoning cases in a tertiary care hospital in Karnataka, India. Indian J Crit Care Med 2009;13:152-5.

6. Jamil H. Acute poisoning--a review of 1900 cases. J Pak Med Assoc 1990;40:131-3.

7. Senewiratne B, Thambipillai S. Pattern of poisoning in a developing agricultural country. Br J Prev Soc Med 1974;28:32-6.

8. Maharani B, Vijayakumari N. Profile of poisoning cases in a tertiary care hospital, Tamil Nadu, India. J Appl Pharm Sci 2013;3:91-4.

9. Kumar SV, Venkateswarlu B, Sasikala M, Kumar GV. A study on poisoning cases in a tertiary care hospital. J Nat Sci Biol Med 2010;1:35-9.

10. Jesslin J, Adepu R, Churi S. Assessment of prevalence and mortality incidences due to poisoning in a South Indian tertiary care teaching hospital. Indian J Pharm Sci 2010;72:587-91.

11. Kanchan T, Menezes RG. Suicidal poisoning in Southern India: Gender differences. J Forensic Leg Med 2008;15:7-14.

12. Kasule M, Malangu N. Profile of acute poisoning in three health districts of Botswana. Afr J Prim Health Care Fam Med 2009; $1: 10$.

13. Smith AJ. Self-poisoning with drugs: a worsening situation. $\mathrm{Br}$ Med J 1972;4:157-9.

14. Chowdhary AN, Banerjee S, Brahma A, Biswas MK. Pesticide poisoning in nonfatal, deliberate self-harm: a public health issue. Indian J Psychiatry 2007;49:117-20.

15. World Health Organization. Media Centre. Suicide: Fact sheet; 2016. Available from: http://www.who.int/mediacentre/ factsheets/fs398/en/. [Last accessed on 10 Jan 2017]

16. Ali MH, Sinha A, Mondal K, Mitra SJ, Mandal A, Maity PK. The scenario of acute poisoning in a subdivision hospital of West Bengal, India. Int J Curr Res Rev 2014;6:53-7.

17. Karki RK, Risal A. Study of poisoning cases in a tertiary care hospital. Kathmandu Univ Med J 2012;10:70-3.

18. Vanishree, Chavan VR, Arshad M, Raghunandan M, Faizuddin. A study on the pattern of acute poisoning in an emergency department of a tertiary care hospital. Asian J Pharm Clin Res 2016;9:361-3.

19. Churi S, Harsha CS, Ramesh M. Patterns of poison information queries received by a newly established South Indian Poison Information Center. Asian J Pharm Clin Res 2012;5:79-82.

\section{How to cite this article}

- $\quad$ Pathan Amanulla Khan, Dileep Chary M, M Manoj Kumar, BB Sarah Nousheen. A study on treatment pattern and outcomes of poisoning cases in a tertiary care and government district hospital. Int J Pharm Pharm Sci 2017;9(4):193-197. 